\title{
MULTIPLE SEX-CHROMOSOMES IN THE MARSUPIAL, POTOROUS
}

\author{
G. B. SHARMAN AND H. N. BARBER \\ Department of Botany, University of Tasmania
}

\section{INTRODUCTION}

Received 3.xii.5I

Since 1922 the cytology of twenty-seven species of marsupials has been investigated (table 1 ). Chromosome numbers in this group are, in general, much lower than those of eutherian mammals and the large size of the chromosomes makes the group favourable for cytological studies. In most of the species studied a typical XY sex-determination mechanism has been reported. Koller (1936) showed that the pairing segments of the $\mathrm{X}$ and $\mathrm{Y}$ chromosomes are terminal or nearly so, and that the centromeres are included in the differential segments. The first meiotic division is therefore reductional. In a preliminary account (Sharman, McIntosh and Barber, 1950) we have shown that in the macropod marsupial Potorous tridactylus three chromosomes in the male are concerned with sex determination and form a trivalent at meiosis. The female has one chromosome less than the male. There appears to be a comparable case in another macropod marsupial Wallabia bicolor (Macropus ualabatus) studied by Agar (1923). Agar considered that the $\mathrm{XY}$ bivalent in this species was "possibly sometimes independent but more often attached to one of the autosomes ". Agar's work has been reinterpreted by Darlington (1937) and Matthey (1949) who considered that a multiple system exists in this marsupial. An examination of Agar's drawings shows that, almost certainly, the same type of multiple system is found in Wallabia as in Potorous, the chromosome number of the former species being the lower by two (Sharman, McIntosh and Barber, 1950). It is probable that a similar mechanism may exist in at least one eutherian mammal, Bovey (1949) having described a trivalent at meiosis in the male of an insectivore, Sorex araneus. The number of chromosomes in the female of this species is unknown but Bovey considers that the system is most likely of the $\mathrm{XY}_{1} \mathrm{Y}_{2}: \mathrm{XX}$ type.

\section{MATERIAL AND METHODS}

The potoroo, Potorous tridactylus Kerr, is a common species of rat kangaroo in Tasmania. This study is based on six specimens, four of which (one female and three males) were obtained in the vicinity of Hobart. A fifth specimen was obtained at Branxholm in north-east Tasmania and a sixth at the Arthur Lakes in Central Tasmania.

Various cytological fixatives were tried but acetic alcohol (one part glacial acetic acid to four parts absolute alcohol) and Champy's fixative 345 
TABLE I

Chromosome numbers and sex-chromosomes in male marsupials *

DIDELPHIDAE

Didelphys autrita

D. paraguayensis

$20+X Y$

D. virginiana

$20+X Y$

Lutreolina crassicaudata

$20+X Y$

$20+X Y$

Dreyfus \& Campos, 1941

Saez, 1931

Painter, 1922

Saez, $193^{8}$

DASTURIDAE

Dasyurops maculatus

(Dasyurus maculatus)

Dasyurus quoll

(D. viverrinus)

Sarcophilus harrisii

(S. ursinus)

$12+X Y$

Greenwood, 1923; Koller, $193^{6}$

$12+\mathrm{XY}$

Drummond, 1938

$12+X Y$

Greenwood, 1923; Koller, 1936

McIntosh \& Sharman, 1952

PERAMELIDAE

Isoodon obesulus

$12+X Y$

Perameles gunii

$12+\mathrm{XY}$

Drummond, 1933; McIntosh \& Sharman, 1952

VOMBATIDAE

Vombatus hirsutus

(Plascolomys mitchellii)

$12+X Y$

McIntosh \& Sharman, 1952

PHASCOLARCTIDAE

Phascolarctos cinereus

PHALANGERIDAE

Petaurus breviceps

Schoinobates volans

(Petauroides volans)

Pseudocheirus peregrinus

Trichosurus vulpecula

$14+X Y$

Greenwood, 1923; Koller, 1936

$20+X Y$

$20+X Y$

Drummond, 1933

$18+\mathrm{XY}$

$18+X Y$

Agar, 1923

\section{MACROPODIDAE}

Bettongia penicillata

B. cuniculus

$26+X Y$

$20+X Y$

$B$. Lesueur

$20+X Y$

$20+X Y$

Setonyx brachyurus

$20+X Y$

$18+X Y$

$14+X Y$

$14+X Y$

Macropus ocydromus

$14+X Y$

Wallabia elegans

(Macropus parryi)

Wallabia rufogrisea

Potorous tridactylus

Wallabia bicolor

(Macropus ualabatus)

$14+X Y$

$10+X Y_{1} Y_{2}$

Altmann \& Ellery, 1925; Koller, 1936

"

"

Drummond, 1933

McIntosh \& Sharman, 1952

Drummond, 1933

McIntosh \& Sharman, 1952

$8+X Y_{1} Y_{2}$

* Where names have been changed since the original papers the name under which the cytology of species was described is inserted beneath in brackets. Names are taken from Iredale and Troughton (1934) which appears to be the latest complete nomenclature list.

(chromic-osmic acid) were found most suitable. For metaphase stages of mitosis and meiosis Champy gave good results, but this fixative was found to be entirely unsuitable for prophase stages of meiosis. Excellent fixation of prophase stages, especially diplotene, was obtained with acetic alcohol. The most satisfactory fixation was obtained by cutting out a small portion from the middle of the testis, quickly dropping it in a tube of fixative, and shaking rapidly with the tube corked. Shaking separates the testis tubules from one another thus ensuring quick fixation. Feulgen squashes, made according to the schedules of Darlington and La Cour (1947), were mainly used but some material was micro- 
tomed at $\mathrm{I}^{-20} \mu$ and stained by the Feulgen method or with crystal violet. Before making Feulgen squashes the bulk-stained material was examined under the microscope using a magnification of approximately $\times$ 40o. Sections of tubule undergoing division were selected and separated from the rest of the material prior to squashing. Faded or badly stained Feulgen preparations can be readily restained by the rapid haematoxylin method of Darlington and La Cour (I947).

Figures and microphotos, unless otherwise stated, appear at a magnification of 2,500 .

\section{MITOSIS AND MEIOSIS}

Male and female somatic chromosomes from spermatogonial or ovarian mitoses are illustrated in fig. I. The male has thirteen chromosomes, the female twelve. In the female six pairs of homologues are easily recognised but in the male three chromosomes are present without
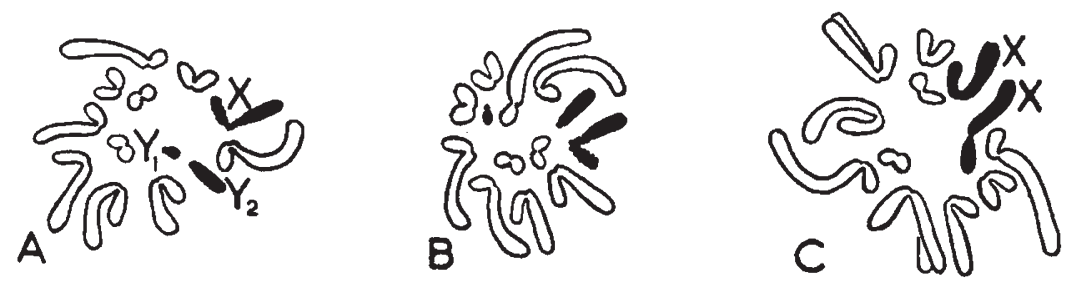

Fig. 1.-Male and female somatic chromosomes. $\times 2,500$.

A. Spermatogonial metaphase; the $\mathrm{X}$ chromosome shows differential condensation.

B. Spermatogonial metaphase; the chromosomes show complete somatic pairing with $\mathrm{Y}_{1}$ left unpaired.

C. Ovarian mitosis from corpus luteum.

equal sized homologues. The largest of these $(\mathrm{X})$ is represented twice in the female (fig. IC). A smaller rod $\left(\mathrm{Y}_{2}\right)$ and a very small chromosome $\left(Y_{1}\right)$ are found in the male only. At metaphase of spermatogonial divisions the $\mathrm{X}$ chromosome of the male consists of two differentially staining parts. The short arm and a portion of the long arm near the centromere are undercondensed relative to the remainder of this chromosome and to the autosomes (fig. IA, B). During the prophase of spermatogonial mitosis this portion of the $\mathrm{X}$ chromosome shows precocious condensation. Precocious condensation of sex chromosomes at mitotic prophase has been reported by Crew and Koller (1932) in the mouse. These observations indicate a cycle of condensation of the sex chromosomes (or their heterochromatic portions) differing from that of the autosomes during mitosis. In some mitotic divisions a centromere constriction and minute second arm can be seen on $\mathrm{Y}_{2}$ (fig. IB), and a slight constriction, which probably corresponds to the centromere can be seen near one end of $Y_{1}$. In some spermatogonial mitoses the chromosomes show complete somatic pairing (fig. IB) as was the case in the marsupial Dasyurus (Koller, I936).

At pachytene (fig. 4B) the three sex chromosomes of the male have 
paired to form a trivalent, consisting at this stage of a deeply stained almost spherical portion connected to a pachytene thread which has the same degree of condensation as the autosomes. The sex elements are thus composed of chromatin of at least two types, one part showing the
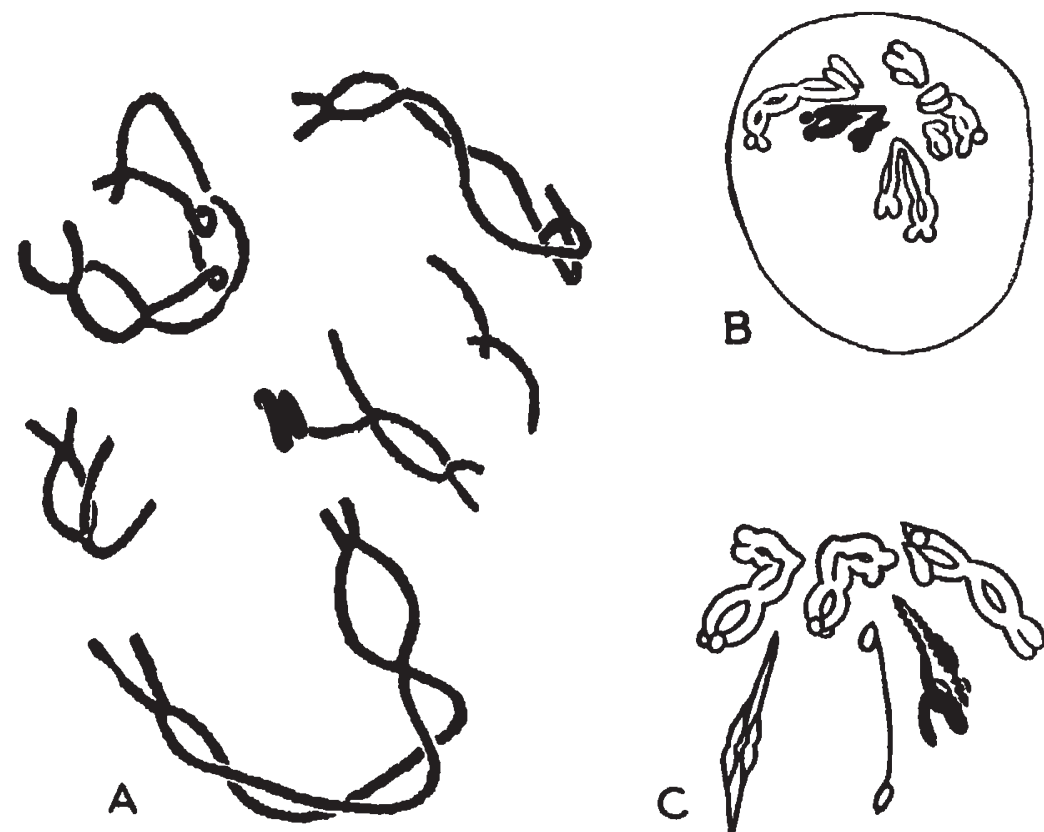

Fig. 2.-Prophase stages of meiosis. $\times 2,500$.

A. Early diplotene; trivalent (at centre) shows condensed and non-condensed portions. One bivalent (top left) broken by squashing.

B. Late diplotene polarisation; trivalent shown in black. (Section.)

C. Early "pre-stretch"; the three longest bivalents are still polarised, the two shortest and the trivalent show pronounced stretch. (Squash.)

early prophase condensation typical of marsupial sex chromosomes, whilst the other part behaves similarly to the autosomes. At early diplotene (fig. 2A) the number of chiasmata per bivalent varies from one (occasionally two) in the shortest bivalent to between three and five in the longest bivalents.

There is no evidence of polarisation at late pachytene or early diplotene. At late diplotene, however, there is a polarised stage at which all the bivalents and the trivalent are attracted to one pole which is apparently determined by the centrosome (fig. 2B). Following polarisation, as the bivalents and trivalent orientate on the spindle, a pronounced "pre-stretch" analogous to that reported by Hughes-Schrader (1943) in mantids occurs. There is a strong repulsion between homologous centromeres and the regions between proximal chiasmata and centromeres are drawn out into long fine threads (figs. 2G, 3A, fig. 5, plate I). Pre-stretch cannot be confused with anaphase movement since the centromeres are separated by a much greater distance during the stretch 
than they are at the onset of first anaphase (fig. 7, plater). The degree of contraction is also much less than at the beginning of anaphase. Following pre-stretch there is a re-approach of the homologous centromeres probably due to a continuation of the coiling of the chromosomes. No previous reports of this type of chromosome behaviour in marsupials have been made, but our observations (McIntosh and Sharman, 1952) show that it occurs in at least six other species.
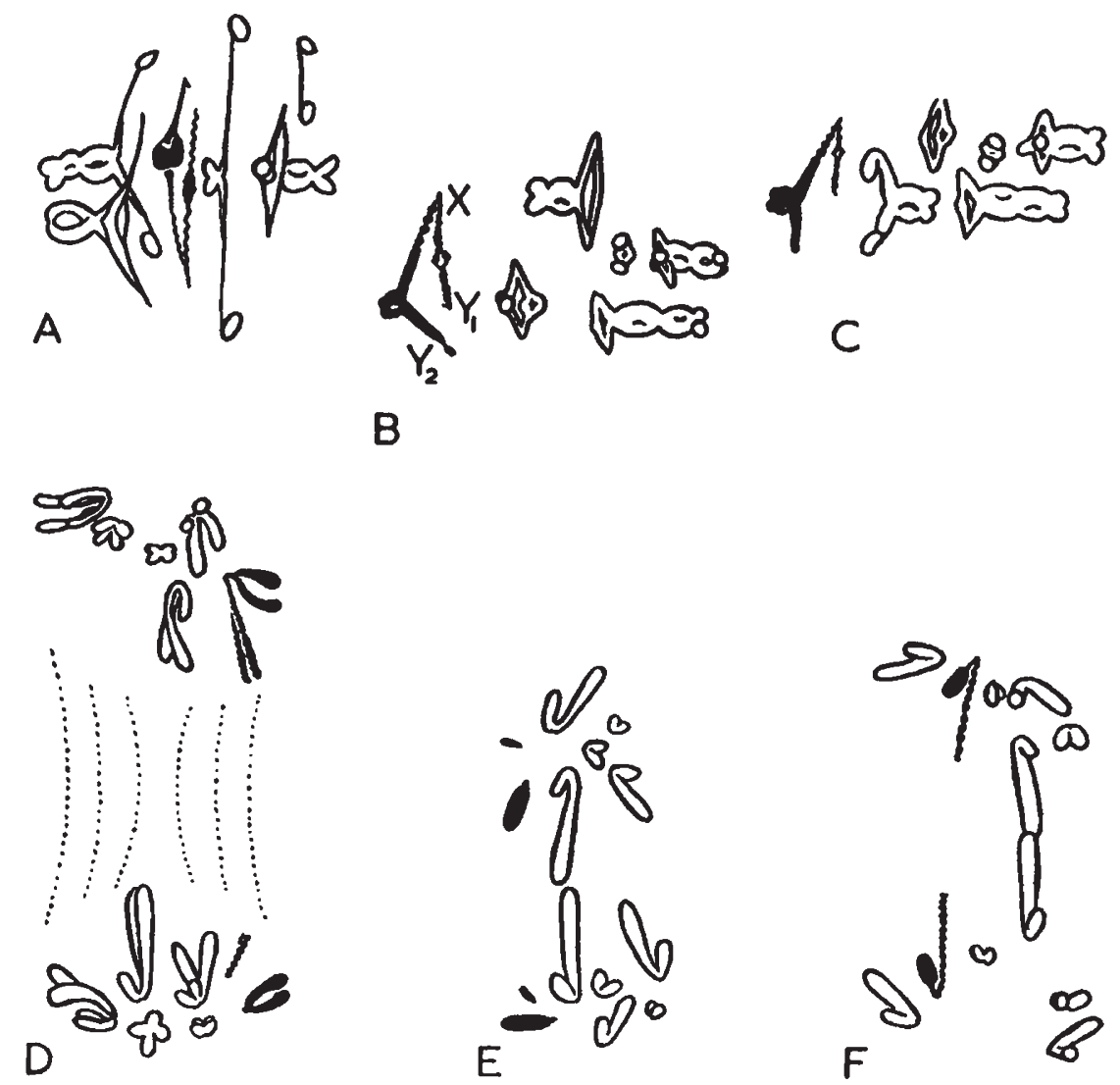

Frg. 3.-Meiosis. $\times 2,500$.
A. "Pre-stretch."
B. First metaphase; one bivalent and the trivalent still slightly stretched; contrac- tion not quite complete.
C. First metaphase; the bivalents show maximum contraction.
D. First anaphase; the heterochromatic portions of the sex chromosomes show
marked undercondensation and increased relative length.
E, F. Second anaphase in cells with seven and six chromosomes; $\mathrm{X}$ chromosome shows pronounced undercondensation in the heterochromatic arm.

The orientation of the trivalent at metaphase is of the convergent type (Darlington, 1937). It orientates (fig. $3 \mathrm{~B}, \mathrm{C}$ ) so that $\mathrm{Y}_{1}$ and $\mathrm{Y}_{2}$ point to one pole and $\mathrm{X}$ to the other. Thus, the first anaphase (fig. $3 \mathrm{D}$ ) leads to the production of secondary spermatocytes with six or seven chromosomes, and two types of spermatid are formed after the second 
meiotic division (fig. $3 \mathrm{E}, \mathrm{F}$ ). These are a male determining type with five autosomes plus $Y_{1}$ and $Y_{2}$ and a female determining type with five autosomes plus $\mathrm{X}$.

The cytology of Tasmanian specimens of Potorous tridactylus has previously been investigated by Ellery (in Altmann and Ellery, r925) who reported both male and female numbers to be twelve and sex determination to be of the XY type. By courtesy of Professor O. W. Tiegs we have re-examined Ellery's slides and find the sex mechanism to be of the $\mathrm{XY}_{1} \mathrm{Y}_{2}: \mathrm{XX}$ type, and the male diploid number to be thirteen as in our material.

\section{STRUCTURE AND BEHAVIOUR OF THE SEX-CHROMOSOMES IN POTOROUS}

The sex trivalent consists of two sets of pairing segments and three unpaired segments with different properties and relationships (fig. 5). The first pairing segments consist of most of $Y_{2}$ and most of the long arm of the $\mathrm{X}$. These segments are completely autosomal in their cycles of nucleic acid attachment and condensation. The second pairing segments, consisting of most of the $Y_{1}$ and of about two-thirds of the short arm of the $\mathrm{X}$, are heterochromatic. They behave in a manner typical of other marsupial X and Y chromosomes (McIntosh and Sharman, I952). They are overcondensed relative to the autosomes until mid-diplotene (fig. $4 \mathrm{~B}, \mathrm{C}$ ) and undercondensed from late diplotene until the end of first anaphase (figs. 4D, E, F, 3D). They are again undercondensed at second anaphase (fig. $3 \mathrm{~F}$ ). At metaphase of spermatogonial mitoses, $\mathrm{Y}_{1}$ is less than half the length of the short arm of the X (fig. 4A). At diplotene however nearly all of the $Y_{1}$ is paired with the short arm of $X$, and these segments appear to be of nearly equal length (fig. 4C, D). These observations probably indicate that the $\mathrm{Y}_{1}$ is more contracted during spermatogonial mitoses than is the heterochromatic portion of the $\mathrm{X}$ chromosome.

The largest of the three unpaired segments is the portion of the $\mathrm{X}$ chromosome containing the centromere. It is a short non-homologous section connecting the two pairing segments (fig. 5), and corresponding to the differential segment of the normal marsupial X chromosome. It is overcondensed during early prophase like the second pairing region (fig. $4 \mathrm{~B}, \mathrm{C}$ ) but often becomes undercondensed earlier. The second unpaired segment is short and contains the centromere of $Y_{2}$ which appears as a non-staining gap at diplotene (fig. 4C, D). The third unpaired segment is a very small section of the $\mathrm{Y}_{1}$ chromosome containing the centromere.

Two chiasmata usually occur in the euchromatic segments. The heterochromatic segments invariably show a single chiasma, which can be clearly seen at late diplotene polarisation (fig. 4D, fig. 4 , plate I). Chiasmata have also been observed in the sex-chromosomes of other macropod marsupials and in Perameles gunnii (McIntosh and Sharman, I952). Koller (r936) is of the opinion that " the association of the sex- 

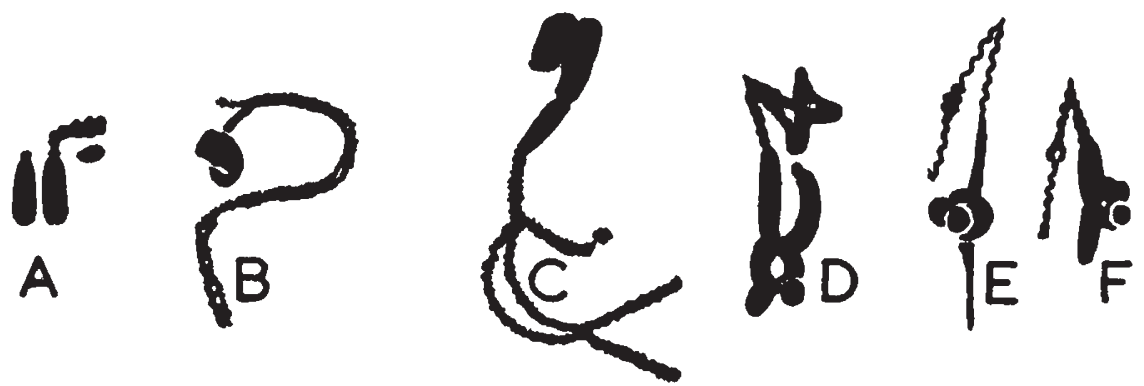

FIG. 4.-The structure of the sex chromosomes at mitosis and meiosis. The figures show the condensation of the heterochromatic portions relative to the remainder. $\times 3,800$.

A. Spermatogonial metaphase.

B. Pachytene; heterochromatic portion overcondensed and in the form of a short tight spiral; differential segment of $\mathrm{X}$ shows as a short non-homologous region.

C. Early diplotene; heterochromatic portion overcondensed and showing differential and pairing segments.

D. Late diplotene polarisation; heterochromatic portion undercondensed and showing the single chiasma between $X$ and $Y_{1}$. Two chiasmata between $X$ and $Y_{2}$.

E. "Pre-stretch."

F. First metaphase; maximum contraction of trivalent.

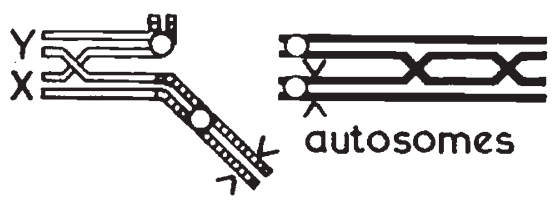

ANCESTRAL XY SYSTEM

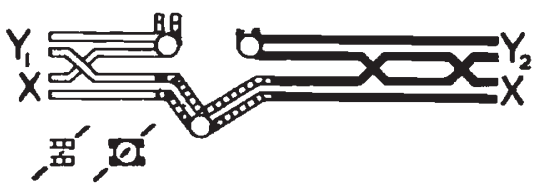

$X Y_{1} Y_{2}$ SYSTEM

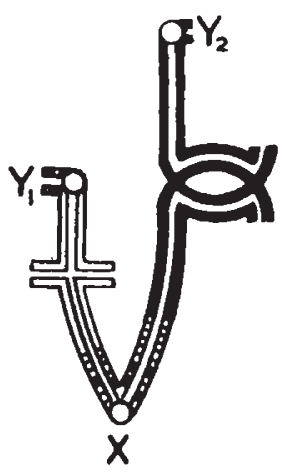

FIG. 5.-The structure of the sex trivalent and its probable method of derivation from an XY system.

chromosomes in the marsupials is without chiasmata and persists as a result of specific attraction based on homology and accentuated by the strong precocious condensation ". As yet we have not examined criti- 
cally the sex chromosomes of any representative of the families studied by Koller.

\section{THE ORIGIN AND EVOLUTION OF SEX-CHROMOSOME MECHANISMS}

A study of sex-chromosomes shows that where the bisexual condition has recently evolved the difference in sex rests on a single gene or a very few genes. The sex chromosomes of such organisms have large euchromatic pairing segments on which free crossing over of many genes is possible, and very small differential segments. Further evolution towards advanced systems such as are found in mammals can take place only if some change, such as inversion, causes the production of differential segments in which crossing over is prevented (Lewis, 1942). The genes on the differential segment of the $\mathrm{Y}$ chromosome are never able to undergo crossing over as this chromosome is held permanently in the heterozygous state. They degenerate by mutation or become lost during evolution. The $\mathrm{X}$ differential only partly suffers from this disadvantage since it can cross over in the homogametic sex. Genes carried on the $\mathrm{X}$ differential segment show complete sex linkage and those carried on the pairing segments partial sex linkage. Both these types of sex linkage are rare in mammals, other than man where complete and partial sex linkage have been demonstrated (Haldane, 1936). Very refined genetic methods are of course necessary to detect partially sex linked genes, so the evidence is at present not sufficient to indicate any definite conclusions (Pontecorvo, 1943). The reasons for the apparent emptiness of the pairing segments are obscure.

The evolutionary path outlined above leads towards genetic inertness and loss of homology of sex chromosomes, a process which may well be more advanced in marsupials than in other mammals. The extremely small size of the $\mathrm{Y}$ chromosome in some marsupials studied by Koller (1936), the very strong precocious condensation of the sex elements at prophase, and their undercondensation at metaphase may be regarded as cytological evidence of near inertness. No genetic evidence is available. Loss of homology and genetic inertness coupled with strong precocious condensation may not always permit pairing and crossing over which will inevitably result in loss during meiosis and a breakdown of the sex-determination mechanism. Koller (1936) has shown that the sex-chromosomes of marsupials are at a disadvantage even before meiosis begins since they are more frequently lost from the cell during spermatogonial mitosis than are the autosomes. Koller also found frequent failure of pairing of the sex elements at meiosis and our observations confirm this in other marsupials (Sharman and McIntosh, I952). No XO sex mechanisms such as are characteristic of some Orthoptera and other groups exist in marsupials yet studied, and indeed their existence has not been proved in any mammal. The most important remaining function of the $\mathrm{Y}$ chromosome may be to pair with and ensure segregation of the all important $\mathrm{X}$ chromosome at meiosis. In 
mammals it is unlikely that difference in sex rests on the presence or absence of a $\mathrm{Y}$ chromosome, but on the $\mathrm{X}$ chromosome-autosome ratio as was demonstrated by Bridges (1922) in Drosophila.

In Potorous the structure and behaviour of the elements of the trivalent at mitosis and meiosis show that it has had autosomal material incorporated into it in some way. $\mathrm{Y}_{2}$ has a nearly terminal centromere and is derived from an autosome, the homologue of which is fused to the ancestral heterochromatic X chromosome. The centromere of the compound $\mathrm{X}$ is contained in the heterochromatic portion and the chromosome is monocentric and not dicentric. This means that one centromere has been lost during the process of fusion. The evidence suggests that the trivalent arose by a reciprocal translocation between the ancestral heterochromatic $\mathrm{X}$ and the homologue of $\mathrm{Y}_{2}$, the centromere of which was lost (fig.5). If, as Muller (1940) suggests, a telomere can never become interstitial then a small terminal portion of heterochromatin from the $\mathrm{X}$ must also have been lost. Prophase configurations show that the position of the break on the homologue of $\mathrm{Y}_{2}$ was almost at the centromere, probably in a short heterochromatic region if such exists at this point in marsupial chromosomes. Little genetically active material would then have been lost during the change.

The new $\mathrm{XY}_{1} \mathrm{Y}_{2}$ system of Potorous does not suffer from the disadvantages of the $\mathrm{XY}$ systems in which the sex elements are largely inert and the pairing segments small. It has benefited by the incorporation of material showing the same cycle of condensation as the autosomes and has an equal chance with them at division. Loss due to non-disjunction in mitotic divisions is not so likely when the $\mathrm{X}$ is permanently attached to an autosome, nor is failure of pairing between $\mathrm{X}$ and $\mathrm{Y}_{2}$ likely at meiosis. $Y_{1}$ is no longer necessary to guarantee segregation of the $\mathrm{X}$ chromosome at meiosis. If it became genetically inert its loss causing reversion to an XY system might be expected.

The addition of autosomal material to the sex-chromosomes has important implications. Sharman, McIntosh and Barber (1950) have suggested that $\mathrm{XY}_{1} \mathrm{Y}_{2}$ system of Wallabia bicolor was formed in the same way as that of Potorous. The multiple system of Sorex araneus also contains autosomal material and probably arose in the same way (Bovey, r949). In all these cases the diploid chromosome number of the female has been reduced by two. Degeneration and disappearance of the small heterochromatic $\mathrm{Y}_{1}$ chromosome would make the male number equal to that of the female. Presumably the new XY system thus formed would be subject to the same laws which governed the evolution of the old XY system, increasing genetic inertness being coupled with loss of homology. The process of incorporation of autosomal material into the sex mechanism which seems to have occurred in all three species would, if it occurred many times, be responsible for an evolutionary trend towards low chromosome numbers. It is, perhaps, significant that the two marsupials have the lowest chromosome numbers recorded in the mammals. In the Eutheria the average chromosome number is approxi- 
mately forty-eight (based on counts of ninety-four species). Sorex araneus has twenty-three chromosomes in the male. It is thus possible that this process may be in part, or wholly, responsible for the low chromosome numbers of marsupials (table I). The $X Y_{1} Y_{2}$ system would then be a stage in " the perpetual cycle of disintegration and replacement of the sex-chromosomes" (Darlington, I939).

\section{SUMMARY}

Potorous tridactylus has 13 chromosomes in the male, 12 in the female. The male has three sex chromosomes $\left(\mathrm{X}_{1}, \mathrm{Y}_{1}\right.$ and $\left.\mathrm{Y}_{2}\right)$ and the female two $\mathrm{Xs}$. In the $\mathrm{X}$ of the male at spermatogonial mitosis, the short arm and a small portion of the long arm are relatively undercondensed.

During meiosis in the male the three sex chromosomes associate and at first division $Y_{1}$ and $Y_{2}$ pass to onc pole and $X$ to the other. The behaviour of the sex chromosomes at mitosis and meiosis shows that they are composed of heterochromatic and euchromatic elements. The short arm of $\mathrm{X}$ and the proximal portion of its long arm together with $\mathrm{Y}_{1}$ show the typical behaviour of marsupial sex chromosomes. Most of the long arm of $X$ and $Y_{2}$ behave like the autosomes. The segment of $\mathrm{X}$ which pairs with $Y_{1}$ is terminal in the short arm and does not include the centromere.

The evolution of sex chromosomes tends towards genetic inertness and loss of homology which may result in non-disjunction at mitosis and failure of pairing at meiosis as has been shown in some marsupials. In Potorous, autosomal material has been incorporated in the sex system, probably by reciprocal translocation, and the sex chromosomes are no longer at a disadvantage in division.

It is suggested that the multiple system of Potorous may represent a stage in a perpetual cycle of disintegration and replacement of sex chromosomes.

This work was carried out while one author was in receipt of a Commonwealth Research Grant. We wish to thank Mr A. G. Lyne and Mr J. M. de Bavay for their assistance in collecting material, and Professor O. W. Tiegs of Melbourne University for supplying some slides of male and female material used by Ellery (1925). The Fauna Board of Tasmania kindly allowed us to take specimens of this protected animal. We also wish to thank Mr A. J. McIntosh for much help and criticism during the investigation.

\section{REFERENCES}

AGAR, W. E. 1923. The male meiotic phase in two genera of marsupials (Macropus and Petauroides). Q.F.M.S., 67, 183-202.

altmann, s. c. A., AND ElLERY, M. E. W. 1925. The chromosomes of four species of marsupials. Q.J.M.S., $69,463-470$.

BOvEy, R. 1949. Les chromosomes des Chiroptères et des Insectivores. Rev. suisse Zool., 56, 371-460.

BRIDGES, C. B. 1922. The origin of variations in sexual and sex limited characters. Amer. Nat., 56, 5 I-623.

CREW, F. A. E., AND KOLLER, P. C. 1932. The sex incidence of chiasma frequency and genetical crossing over in the mouse. F. Genet., 26, 359-383. 
DARLington, C. D. 1937. Recent Advances in Cytology. London: Churchill.

DARLington, G. D. 1939. The Evolution of Genetic Systems. Cambridge: University Press.

Darlington, C. D., AND LA cour, L. F. 1947. The Handling of Chromosomes (second edition). London: Allen and Unwin.

DREYFUS, A., AND CAMPOS, J. E. 1941. Estudos sobre cromosomas de Marsupiais Brasileiros. Univ. Sāo Paulo. Bol. Fac. Fil., Ciên. e Letr. 17. Biol. Ger., 3, 3-28.

DRUMMOND, F. H. 1933. The male meiotic phase in five species of marsupials. Q.J.M.S., 76, I-I I.

DRUMmoNd, F. H. 1938. Meiosis in Dasyurus viverrinus. Cytologia, 8, 343-352.

GREENWOOD, A. w. 1923. Marsupial spermatogenesis. Q.J.M.S., 67, 203-218.

HALDANE, J. B. s. 1936. A search for incomplete sex linkage in man. Ann. Eugen., $7,28-57$.

HUGHeS-schrader, s. I943. Polarisation, kinetochore movements, and bivalent structure in the meiosis of male mantids. Biol. Bull., $85,265-300$.

IREDALE, T., AND TROUGHTON, E. LE G. 1934. A check list of mammals recorded from Australia. Aust. Mus. Sydney, Mem. VI.

KOLleR, P. c. 1936. The genetical and mechanical properties of the sex chromosomes. II. Marsupials. 7. Genet., 32, 451-472.

LEWIS, D. 1942. The evolution of sex in flowering plants. Biol. Rev., $17,46-67$.

MciNTOSH, A. J., AND SHARMAN, G. B. I952. Unpublished results.

MATthex, R. 1934. La formule chromosomiale du kangourou Macropus parryi Benn. C.R.S.B., ${ }_{I I 7} 7,406-407$.

MATTHEY, R. 1936. Le problème des hétérochromosomes chez les Mammifères. Arch. Biol., 47, 319-383.

MatThex, R. 1949. Les Chromosomes des Vertébrés. Lausanne : F. Rouge.

MULLER, H. J. 1940. Bearings of the Drosophila work in systematics. (Article in The $\mathcal{N}$ ew Systematics, edited by J. S. Huxley. Oxford : University Press.)

PAINTER, T. s. 1922. Studies in mammalian spermatogenesis. I. The spermatogenesis of the opossum (Didelphys virginiana). $\mathcal{F}$. Exp. Zool., 35, 13-38.

Pontecorvo, G. 1943. Meiosis in the striped hamster (Cricetulus griseus Milne-Edw.) and the problem of heterochromatin in mammalian sex chromosomes. P.R.S. Edinb., B, 62, 32-42.

SAEZ, F. A. 1931. The chromosomes of the South American opossum, Didelphys paraguayensis. Amer. Nat., $65,{ }^{\prime} 287-388$.

SAEZ, F. A. 1938. Investigaciones citologicas sobre los marsupiales sudamericanos. R. Soc. Argentina Biol., 14, 156 -161.

SHARMAN, G. B., Mcintosh, A. J., AND BARBER, H. N. I950. Multiple sex chromosomes in the marsupials. Nature, ${ }^{166} 6,996$. 
Plate I.-... Squashes of Potorous tridactylus. $\times 2,500$.

Cir.-Fixation in Champy's fixative. $1: 3$-Fixation in $1: 3$ acetic alcohol. 1:4-Fixation in $1: 4$ acetic alcohol. Feul.-stained in Fculgen's leuco-basic fuchsin.

Fir. I.-Spermatogonial metaphasc: $Y_{2}$ and $\mathrm{X}$ at one o'clock in upper cell. 'I'he heterochromatic portion of $\mathrm{X}$ is undercondensed (c.f. fig. IB), Ch., Fcul.

Fis. 3.-Diplotene; trivalent at centre. : I4, Feul. restained in haematoxylin.

FIG. 2.- Metaphase of mitosis from corpus luteum ; two $\mathrm{X}$ chromosomes at threc o'clock (c.f. fig. Ic). I : 3, Feul.

Fis. 5-- "Pre-stretch": trivalent at left. $i: 1$, Frul.

FIs. 4.-Late diplotene polarisation, considerably displaced by squashing; trivalent at three o'clock showing single chiasma between $X$ and $Y_{1}{ }^{\circ} \quad I: 4$, Feul. restained in haemotoxylin.

Fis. 6.-First metaphase; trivalent at left. (c.f. fig. 3A). The object below the plate is a spermatid. Ch., Feml.

Fic. 7.- Early first anaphase ; one bivalent and a $X-Y_{1}$ portion of trivalent (at right) have separated. Ch., Fenl., restained in haematoxylin. 
